Jurnal Konstruksi Hukum | ISSN: 2746-5055

Vol. 2, No. 1, Januari 2021 Hal. 19-23 | Tersedia online di https://www.ejournal.warmadewa.ac.id/index.php/jukonhum

DOI: https://10.22225/jkh.2.1.2961.19-23

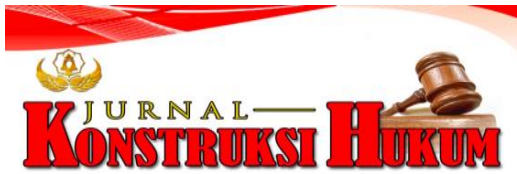

\title{
UANG VIRTUAL (CRYPTOCURRENCY) SEBAGAI SARANA TINDAK PIDANA PENCUCIAN UANG DALAM PERDAGANGAN SAHAM
}

\author{
Dewanti Arya Maha Rani, I Nyoman Gede Sugiartha, Ni Made Sukaryati Karma \\ Fakultas Hukum Universitas Warmadewa, Denpasar-Bali, Indonesia
}

\begin{abstract}
Abstrak
Kelanjutan media elektronik yang ramai diperbincangkan saat ini yaitu uang virtual biasa disebut dengan cryptocurrency. Cryptocurrency dapat juga disebut sebagai benda niaga tidak terbentuk; sejatinya berwujud digital dimana dapat dipakai dalam transaksi elektronik. Penelitian ini bertujuan untuk menganalisis eksistensi uang virtual (cryptocurrency) dalam perdagangan saham di Indonesia dan mengetahui tanggung jawab pelaku tindak pidana pencucian uang yang meggunakan uang virtual (cryptocurrency) dalam perdagangan saham. Metode penelitian yang digunakan adalah penelitian hukum normative. Hasil penelitian menunjukan bahwa Eksistensi uag virtual (cryptocurrency) dalam perdagangan saham di Indonesia ketika dijadikan unifikasi mata uang, bertransaksi, berniaga ataupun sebagai alat pembayaran dengan bisnis dalam hal ini khususnya perdagangan saham di Indonesia dapat dikatakan tidak sah penggunaannya ditinjau dari Undang-undang Nomor 7 Tahun 2011 Tentang Mata Uang. Pengguna uang virtual (cryptocurrency) di Indonesia cukup banyak digunakan dalam hal bisnis, yang dimana dapat dilihat di Indonesia sendiri sudah beredar uang virtual (cryptocurreny) seperti Bitcoin dan Centcoin. Kemudian, tanggungjawab pelaku tindak pidana pencucian uang yang menggunakan uang virtual (Cryptocurrency) dalam perdagangan saham yang dimana perbuatan tersebut sangat berdampak negative bagi Negara Indonesia, terutama dalam hal bisnis dikarenakan orang yang telah melakukukan kejahatan tersebut memanfaatkan kemajuan teknologi dengan tidak bijak sehingga pelaku dapat dijerat berdasar pada Undang-undang No. 8 Tahun 2010 tentang pencegahan dan pemberantasan tindak pidana pencucian uang.
\end{abstract}

Kata kunci: Uang Virtual, Cryptocurrency, Tindak Pidana Pencucian Uang

\begin{abstract}
The continuation of the electronic media that is widely discussed today is virtual money, commonly known as cryptocurrency. Cryptocurrency can also be referred to as an unformed commercial object; actually in digital form which can be used in electronic transactions. This study aims to analyze the existence of virtual money (cryptocurrency) in stock trading in Indonesia and to find out the responsibilities of money laundering offenders who use virtual money (cryptocurrency) in stock trading. The research method used is normative legal research. The results show that the existence of virtual money (cryptocurrency) in stock trading in Indonesia when used as currency unification, transact, trade or as a means of payment with businesses in this case, especially stock trading in Indonesia can be said to be invalid in terms of Law Number 7. 2011 concerning Currency. Users of virtual money (cryptocurrency) in Indonesia are quite widely used in business, which can be seen in Indonesia itself that virtual money (cryptocurreny) such as Bitcoin and Centcoin are circulating. Then, the responsibility of the perpetrators of money laundering who use virtual money (Cryptocurrency) in stock trading, where this action has a very negative impact on the Indonesian State, especially in terms of business because people who have committed these crimes take advantage of technological advances unwise so that the perpetrators can be ensnared based on Law No. 8 of 2010 concerning the prevention and eradication of the crime of money laundering.
\end{abstract}

Keywords: Virtual Money, Cryptocurrency, Money Laundering Crime

\section{PENDAHULUAN}

Indonesia merupakan Negara yang berdasarkan hukum. Hukum memiliki karakteristik mengendalikan serta menuntut seseorang agar patuh terhadap aturan yang dibuat dan selanjutnya menetapkan aturan tersebut sehingga fungsi hukum dapat berjalan sesuai dengan fungsinya sendiri. Hukum yang diproduksi oleh manusia dalam hal ini terdapat ketentuan-ketentuan yang harus dijalankan serta menetapkan suatu tindakan yang berlaku bagi warga Negara, sehingga makna yang dimaksud yaitu, hukum yang berlangsung di Negara Kesatuan Republik Indonesia pada waktu saat ini disebut "Hukum Positif", yang memiliki makna hukum yang berlaku bagi seluruh warga Negara Republik 
Indonesia. Di Indonesia hukum nasional tersusun secara sistematis berdasarkan hierarkis dan berpedoman kepada cita hukum Pancasila, sehingga dapat diimplementasikan ke dalam kenyataan melalui dasar-dasar hukum nasional melaui perundang-undangan dan yurisprudensi pada proses penyusunan hukum positif. Hukum senantiasa berjalan maju dan tanggap tentang beragam macam perkembangan yang baru terjadi di masyarakat. Artinya, kemajuan hukum selalu senantiasa tertinggal dengan berkembangnya di aspek- aspek baru seperti dalam aspek sosial, teknologi, dan lain-lain.

Akibat yang lebih dominan dengan adanya kemunculan perkembangan teknologi pada seluruh bagian kehidupan saat ini yaitu bermacam tantangan potensial yang ditemui oleh individu-individu pada umumnya. Dapat disimpulkan bahwa kemajuan teknologi juga sangat berpengaruh pada bidang ekonomi, seperti bertransaksi dalam bisnis dengan cara tidak menggunakan uang secara tunai melainkan memanfaatkan kemajuan teknologi melalui pendapatan dan pergerakan modal dengan waktu yang efisien yang menimbulkan kecenderungan kekhawatiran dengan permasalahan penyalahgunaan yang memicu suatu konsekuensi yang tidak diinginkan.

Kelanjutan alat elektronik yang ramai diperbincangkan saat ini yaitu mengenai uang virtual yang disebut dengan cryptocurrency, selanjutnya penuliasan uang virtual (cryptocurrency) akan disebut dengan cryptocurrency. Cryptocurrency dapat disebut dengan benda niaga tanpa menggunakan uang tunai, berbentuk digital serta dapat dijadikan untuk transaksi elektronik. Mata uang virtual adalah uang digital yang merupakan hasil dari suatu teknologi melalui sistem kriptografi bertujuan untuk memberikan jaminan keamanan dengan tidak bias ditiru. Kriptografi adalah sebuah teknik untuk memungkinkan transmisi informasi yang aman (Kelly, 2018). Dampak penggunaan cryptocurrency dilihat dari prospek hukum Indonesia dapat memicu bermacam- macam kejahatan yang menimbulkan kerugian dari beberapa bagian, yaitu ekonomi, hukum ataupun keamanan Negara. Perkembangan cryptocurrency dapat menjadi salah satu modus baru tindak pidana pencucian uang dalam hal ini dapat dikatakan juga money laundering dikarenakan terdapat potensi money laundering tersebut berdasarkan menggunakan tanda tangan digital dan penggunaan identitas palsu. Sebab tindakan ini bertujuan untuk menyamarkan dana serta beragam informasi dari transaksi dengan mata uang virtual yaitu cryptocurrency, yang sejatinya adalah mata uang tanpa bentuk fisik yang dibentuk dengan teknologi informasi.

Cryptocurrency yang saat ini menguasai dunia internasional sekarang ini adalah Bitcoin Bitcoin merupakan bentuk mata uang cryptocurrency dapat dikatakan seperti mata uang digital yang berada dalam jaringan peer-to-peer ( $\mathrm{P} 2 \mathrm{P})$ merupakan tipe jaringan yang berkebalikan dengan tipe serverbased. Pada sistem tersebut computer bertindak sebagai server dimana yang akan melayani permintaan informasi ataupun pengolahan data yang datang dari klien. Pada jaringan P2P semua komputer dikatakan sebagai node dimana dapat terhubung pada jaringan bertindak sebagai server dan dapat juga menjadi klien. Jaringan peer-to-peer mempermudah pengguna untuk berinteraksi secara langsung tanpa menggunakan jasa dari pihak ketiga.

Tindak pidana pencucian uang merupakan tindak pidana khusus. Tindak pidana khusus dapat diartikan menjadi perundang-undangan di bagian khusus yang mempunyai sanksi pidana dalam hal ini diatur pada perundang-undangan khusus di luar (Kitab Undang-Undang Hukum Pidana), baik perundang-undangan pidana maupun bukan pidana tetapi memiliki sanksi pidana (Syamsuddin, 2016). Indonesia merupakan Negara yang sedang berkembang yang menjadi tujuan para pengusaha didalam maupun luar negeri byang bertujuan memperbanyak dan meningkatkan kekayaan dengan cara membeli dan menjual saham yang dapat berbentuk suatu investasi. Saham adalah surat berharga yang dapat diniagakan pada bursa efek. Adapun pengertian dari saham adalah surat bukti sebuah perusahaan kepemilikan yang melangsungkan penawaran umum dengan jumlah persentase yang telah ditentukan atas sebuah perusahaan yang melakukan penawaran umum (go public) dalam nominal dan porsentase tertentu. Suatu modal responsive yang satuan sama jumlahnya dapat diputar atas bermacam cara berniaga dan juga harga dapat berubah sewaktu-waktu bergantung pada kerugian dan keuntungan kinerja perusahaan itu (Manan, 2009). Dengan demikian, penelitian ini bertujuan untuk menganalisis eksistensi uang virtual (cryptocurrency) dalam perdagangan saham di Indonesia dan mengetahui tanggung jawab pelaku tindak pidana pencucian uang yang meggunakan uang virtual (cryptocurrency) dalam perdagangan saham. 


\section{METODE PENELITIAN}

Penelitian ini menggunakan metode penelitian hukum normative; penelitian yang menganalisis hubungan dan penyelarasan antara asas hukum, norma hukum, dan pendapat sarjana (teori-teori) serta aturan lainnya terkait dengan pokok masalah yang dibahas (Aziz, 2012). Pendekatan masalah yang digunakan yaitu peraturan perundang-undangan dan pendekatan konseptual. Peraturan perundangundangan yang dimaksud yaitu peraturan tertulis dimana tersirat dalam lembaran Negara serta ditetapkan oleh pejabat yang berwenang melalui ketentuan-ketentuan yang telah ditetapkan dan didalamnya termuat suatu norma yang mengikat setiap orang secara umum. Sementara, pendekatan konseptual merupakan konsep yang berkembang di dalam masyarakat.

Sumber bahan hukum yang digunakan dalam penelitian ini yaitu bahan hukum primer merupakan bahan hukum yang bersifat autoritatif, memiliki arti, dimana lembaga yang berwenang menghasilkan suatu hasil tindakan dan kegiatan, bebas bereksperimen akan tetapi memiliki suatu batasan (Marzuki, 2011). Undang - Undang Dasar Negara Kesatuan Republik Indonesia Tahun 1945, Kitab Undang - Undang Hukum Pidana, Undang - Undang Nomor 7 Tahun 2011 tentag Mata Uang, Undang - Undang Nomor 8 Tahun 2010 tentang Pencegahan Dan Pemberantasan Tindak Pidana Pencucian Uang, Undang- Undang Nomor 8 Tahun 1995 tentang Pasar Modal, Peraturan menteri Perdagangan Republik Indonesia Nomor 99 Tahun 2018, Peraturan Badan Pengawas Perdagangan Berjangka Komoditi Nomor 5 Tahun 2019.

Bahan hukum sekunder yaitu pengumpulan bahan hukum yang didapat dari peraturan perundangundangan, berbagai bacaan atau literatur-literatur, serta pendapat para sarjana (doktrin) yang relevan dengan kajian penelitian ini.

\section{HASIL DAN PEMBAHASAN}

\section{Eksistensi Uang Virtual (Cryptocurrency) dalam Perdagangan Saham di Indonesia}

Pasar modal yaitu tempat pertemuan dilakukannya suatu transaksi yang melibatkan pencari dana dan para penanam modal. Adapun kegiatan pasar modal yang diniagakan yaitu efek-efek, contohnya adalah obligasi dan saham bilamana kegiatan ini memiliki jangka waktu yang panjang (Kasmir, 2017).

Berkembangnya suatu teknologi informasi dan komunikasi yang semakin cepat, memiliki suatu keharusan secara teliti dan optimis. Melihat kemajuan peluang bisnis yang mengarah ke digital atau dunia maya adalah peluang yang dapat menjanjikan bagi setiap orang yang berkecumbung di dalam bisnis tersebut. Dunia sekarang ini mengarah ke arah aktual yaitu menggunakan uang virtual (cryptocurrency) tidak lagi menggunakan uang tunai seperti uang kertas ataupun logam. Diketahui bahwa asal muasal adanya uang disebabkan masyarakat merasakan kesusahan dalam menjalankan tukar menukar yang dapat disebut degan barter. Barter merupakan suatu kegiatan tukar menukar barang ataupun jasa. Disisi lain wilayah cakupan barter ini lebih sempit disebabkan kesulitan orang tersebut untuk bertemu satu sama lain.

Cryptocurrency diciptakan menggunakan kriptografi yang bertujuan untuk tidak mudah ditiru dengan mekanisme yang sangat rumit dikarenakan agar tidak dapat digandakan dan mudah berpindah tangan jika tidak memiliki akses atau jaringan pada cryptocurrency tersebut. Saat ini ditemukan mulai banyaknya cryptocurrency yang digunakan dikalangan masyarakat dengan tujuan bermacam bertransaksi. Cryptocurrency dapat melakukan pemeriksaan setiap pengiriman dana yang melaksanakan kegiatan tersebut tanpa campur pihak ketiga seperti bank sentral. Saat ini di Indonesia sudah beredar mata uang virtual (cryptocurrency), seperti Cryptocurrency (Bitcoin) dan Cryptocurrency (Centcoin).

Sebagaimana dalam karakteristik cryptocurrency yang memanfaatkan teknik-teknik kriptografi dalam sistemnya terdapat dua teknik yang penting dalam system cryptocurrency yaitu tanda tangan digital dan fungsi hash.

a. Tanda tangan digital

Tanda tangan digital ini adalah komponen yang penting dikarenakan secara umum terdapat manfaat yaitu untuk memastikan dan mengetahui identitas dari tanda tangan digital tersebut, memastikan orang tersebut agar tidak bisa menyangkal, memastikan dokumen yang dibubuhi tanda tangan tidak adanya perubahan.

b. Fungsi Hash 
Fungsi hash adalah fungsi yang bertujuan untuk mengkalkulasi nilai dari sebuah data. merupakan sebuah fungsi yang digunakan untuk menghitung nilai unik dari sebuah data berukuran sembarang. Manfaat fungsi hash bertujuan untuk melindungu data kerahasiaan dan memastikan data tidak dapat dirubah serta dapat memproduksi mempresentasikan data.

Kemunculan mata uang virtual cryptocurrency di Indonesia saat ini sangat mendapatkan respon yang positif serta memberikan efek keingintahuan seseorang mengenai cryptocurrency tersebut. Seiring berjalannya waktu cryptocurrency berkembang pesat karena dapat dipergunakan sebagai sarana investasi, berniaga, ataupun pembayaran melalui system elektronik. Diperhatikan berdasarkan konsep cryptocurrency merupakan jembatan alternatif mata uang dunia yang benar-benar berpedoman pada supply dan demand, berhubungan antara banyaknya permintaan sehingga terjadinya kenaikan harga serta banyaknya jumlah barang yang ditawarkan sehingga sebaliknya mengalami penurunan harga. Penggunaan cryptocurrency di kalangan masyarakat mendorong Bank Indonesia mengeluarkan yang dimana Bank Indonesia menghimbau bagi pengguna cryptocurrency agar bijak dan berhati-hati dalam menggunakan cryptocurrency. Disebabkan cryptocurrency belum memiliki aturan secara spesifik mengatur dan tidak diakui juga cryptocurrency sebagai alat pembayaran yang legal di Indonesia.

Badan Pengawas Perdagangan Berjangka Komoditi (BAPPEBTI) bersinergi melakukan suatu penilaian dan relevansi adanya cryptocurrency bagi perkembangan perekonomian ataupun dalam hal bisnis. Sejatinya BAPPEBTI telah menyatakan cryptocurrency sebagai subjek komoditi dalam bursa perdagangan berjangka. Berbicara mengenai uang, tentu dapat dilihat bahwa uang mengalami perkembangan dari waktu ke waktu. Jika dulu uang hanya berbentuk fisik, sekarang terdapat uang dalam bentuk virtual. Seiring perkembangan jaman, muncul pula berbagai cara bagi masyarakat untuk menimbun kekayaannya seperti dengan melakukan jual-beli mata uang virtual sebagai salah satu bentuk investasi yang dapat dicairkan kapan saja.

\section{Tanggung Jawab Pelaku Tindak Pidana Pencucian Uang yang Meggunakan Uang Virtual (Cryptocurrency) dalam Perdagangan Saham}

Hukum Pidana merupakan hukum yang mengandung peraturan- peraturan yang didalamnya terdapat suatu kemestian, kewajiban, dan larangan kepada pelanggarnya yang dapat diancam hukuman yaitu suatu siksa badan (Gunaedi \& Effendi, 2015). Pesatnya kemajuan teknologi memunculkan berbagai bentuk kejahatan yang memiliki jaringan internasional dimana lembaga keuangan merupakan suatu sarana dan sasarannya, hal ini dapat dikatakan seperti kejahatan toindak pidana pencucian uang (money loundering).

Tindak pidana pencucian uang tidak berdiri sendiri karena harta kekayaan yang ditempatkan, dipindahkan, atau dialihkan dengan cara pembaruan yang diperoleh dari tindak pidana, dalam hal ini telah ada tindak pidana lain yang mendahuluinya. (Predicate Crime). Menurut, Sutedi (2008), pencucian uang adalah kegiatan yang memimiliki tujuan untuk menyembunyikan asal muasal uang ataupun harta kekayaan itu berasal dan selanjutnya dimanipulasi sedemikian rupa menjadi harta kekayaan yang seolah-olah berasal dari kegiatan yang legal. Adanya cryptocurrency menimbulkan indikasi kejahatan tindak pidana pencucian uang, strategi utama yang dilakukan adalah (follow the money) mengikuti uang. Cryptocurrency dan mata uang serupa seringkali digunakan secara luas untuk kejahatan, tetapi mereka belum sepenuhnya berada dalam radar peradilan pidana. Adanya cryptocurrency telah menimbulkan risiko yang signifikan atau hanya merupakan potensi ancaman menjadi sebuah kewajiban lembaga penegak hukum untuk memastikan bahwa risiko yang ada atau potensial lebih diakui dan dipahami secara luas

\section{SIMPULAN DAN SARAN}

\section{Simpulan}

Eksistensi uag virtual (cryptocurrency) dalam perdagangan saham di Indonesia ketika dijadikan unifikasi mata uang, bertransaksi, berniaga ataupun sebagai alat pembayaran dengan bisnis dalam hal ini khususnya perdagangan saham di Indonesia dapat dikatakan tidak sah penggunaannya ditinjau dari Undang-undang Nomor 7 Tahun 2011 Tentang Mata Uang. Pengguna uang virtual (cryptocurrency) di Indonesia cukup banyak digunakan dalam hal bisnis, yang dimana dapat dilihat di Indonesia sendiri sudah beredar uang virtual (cryptocurreny) seperti Bitcoin dan Centcoin. Kemudian, tanggungjawab pelaku tindak pidana pencucian uang yang menggunakan uang virtual (Cryptocurrency) dalam 
perdagangan saham yang dimana perbuatan tersebut sangat berdampak negative bagi Negara Indonesia, terutama dalam hal bisnis dikarenakan orang yang telah melakukukan kejahatan tersebut memanfaatkan kemajuan teknologi dengan tidak bijak sehingga pelaku dapat dijerat berdasar pada Undang-undang No. 8 Tahun 2010 tentang pencegahan dan pemberantasan tindak pidana pencucian uang.

\section{Saran}

Pemerintah memiliki suatu kewenangan dalam menjalankan tugas yang telah ditentukan. Diharapkan dalam hal ini pemerintah dapat merevisi kembali Undang-undang yang terkait dengan cryptocurrency, serta dapat membuat aturan khusus mengenai cryptocurrency tersebut agar keberadaannya jelas dan relevan dikalangan masyarakat dikarenakan terkait dengan bahwa sampai sekarang Indonesia belum mempunyai aturan yang jelas tentang penggunaan uang virtual (cryptocurrency). Bagi pengguna cryptocurrency diharapkan selalu berhati-hati dan bijak dalam menggunakan pengaplikasian asset digital tersebut, agar tidak terjadi kejadian yang tidak diinginkan.

Selanjutnya, pemerintah harus lebih berperan dalam hal ini disebabkan kasus tindak pidana pencucian uang memberikan dampak yang sangat negative bagi Negara dan menimbulkan suatu kerugian yang sangat besar. Oleh sebab itu pemerintah dapat bekerjasama terhadap lembaga terkait seperti kepolisian disebabkan terungkapnya kasus selalu diawali dengan terbongkarnya tindak pidana awal yang telah dilakukan oleh pelaku. Disisi lain pemerintah diharapkan dapat memblokir situs ataupun penyedia cryptocurrency yang berjalan secara illegal sebelum aturan tentang cryptocurrency disahkan. Sebab cryptocurrency dapat sebagai sarana untuk melakukan pencucian uang.

\section{DAFTAR PUSTAKA}

Aziz, N. M. (2012). Urgensi Penelitian dan Pengkajian Hukum dalam Pembentukan Peraturan PerundangUndangan. Jurnal RECHTS VINIDNG: Media Pembinaan Hukum Nasional, 1(1), 17-31.

Gunaedi, I., \& Effendi, J. (2015). Cepat dan Mudah Memahami Hukum pidana. Jakarta: Kencana. Kasmir. (2017). Bank dan Lembaga Keuangan Lainnya. Jakarta: Rajawali Pers.

Kelly, B. (2018). The Bitcoin Big Bag. Jakarta: Elex Media Komputindo.

Manan, A. (2009). Aspek Hukum dalam Penyelenggaraan Investasi di Pasar Modal Syariah Indonesia. Jakarta: Kencana Media Group.

Marzuki, P. M. (2011). Penelitian Hukum. Jakarta: Kencana Prenida Media.

Sutedi, A. (2008). Tindak Pidana Pencucian Uang. Bandung: Citra Aditya Bakti.

Syamsuddin, A. (2016). Tindak Pidana Khusus. Jakarta: Sinar Grafika. 